Juergen Kammler

Alexander Kypta

Robert Hofmann

Klaus Kerschner

Michael Grund

Kurt Sihorsch

Clemens Steinwender

Thomas Lambert

Wolfram Helml

Franz Leisch
Received: 14 March 2008

Accepted: 7 October 2008

Published online: 30 October 2008
The authors have no financial associations that might pose a potential conflict of interest with the paper to disclosure.

J. Kammler, MD ( $\varangle) \cdot$ A. Kypta, MD

R. Hofmann, MD $\cdot$ K. Kerschner, MD

M. Grund, MD - K. Sihorsch, MD

C. Steinwender, MD - T. Lambert, MD

F. Leisch, MD

Cardiovascular Division

General Hospital Linz

Krankenhausstr. 9

4020 Linz, Austria

Tel.: +43-732/7806-73213

Fax: +43-732/7806-6205

E-Mail: juergen.kammler@akh.linz.at

W. Helml, PD

Max-Planck-Institute of Quantum Optics Munich, Germany

\section{TIMI 3 flow after primary angioplasty is an important predictor for outcome in patients with acute myocardial infarction}

Abstract Background Growing evidence suggests that poor coronary blood flow after primary percutaneous coronary intervention (PCI) is associated with unfavorable clinical out-come. We retrospectively evaluated data from our single center "real world patients" database of patients undergoing primary PCI to determine differences in clinical and angiographic patterns in patients with or without restoring thrombolysis in myocardial infarction (TIMI) flow 3. Methods and results Between 2001 and 2006, 500 patients underwent primary PCI for STEMI. In 430 patients, post-interventional TIMI flow 3 could be established. In this group, in-hospital mortality was significant lower $(6.4 \%$ Vs. $32.9 \%$; $P<0.0001)$, left ventricular ejection fraction was better $(51.3$ Vs. $44.2 \%$; $P<0.0001)$, and prehospital fibrinolytic therapy $(6.3 \%$ Vs. $14.3 \%$; $P=0.015)$, cardiogenic shock $(10.9 \%$ Vs. $24.3 \% ; P=0.002)$ and use of intra-aortic balloon pump were all more unlikely (5.8\% Vs. $11.4 \%$; $P=0.045)$ compared to patients with TIMI flow $\leq 2$. In patients with post-interventional TIMI flow $\leq 2$ the left anterior descending coronary artery (LAD) was significantly more often seen as the target vessel $(54.3 \%$ Vs. $44.6 \% ; P=0.039)$. A regressions analysis showed that predictors leading to such flow patterns are diabetes $(P=0.013)$, pre-hospital fibrinolytic therapy $(P=0.017)$, cardiogenic shock $(P=0.002)$ and a 3vessel disease $(P=0.003)$. After 6 months, patients without restored normal TIMI flow had worse New York Heart Association functional class (NYHA), and had to undergo repeat coronary angiography more often. Conclusion Post-interventional TIMI flow $\leq 2$ is strongly associated with adverse out-come during hospitalization and after 6 months following hospitalization.

Key words TIMI flow - primary percutaneous coronary intervention - acute myocardial infarction - follow up no reflow phenomenon

\section{Introduction}

Reperfusion therapy is the cornerstone of treatment for patients with acute ST-elevation myocardial infarction (STEMI). Timely reperfusion of the infarctrelated coronary artery using fibrinolysis or PCI is central to optimal STEMI treatment $[1-3,10,15,18]$. As our treatment center has a skilled PCI laboratory with an experienced interventional cardiologist on duty $24 \mathrm{~h}$ a day, patients admitted to our hospital undergo primary PCI if coronary arteries are suitable, as recommend in current standard guidelines [1] within $<90$ min door-to-balloon time. 
The benefits of reperfusion therapy have been attributed to the prompt reestablishment of normal blood flow in the infarct-related artery, defined as thrombolysis in myocardial infarction (TIMI) 3 flow.

We investigated the clinical outcome at index hospitalisation and after 6 months in groups of patients with or without re-established TIMI three flow, using data from our acute PCI database of a "real world" outdoor patient cohort of 500 patients treated between February 2001 and October 2006.

\section{Methods}

\section{Patient population}

Results from 500 consecutive patients treated with acute PCI in acute STEMI were retrospectively acquired. STEMI was defined as typical ischemic chest pain within the previous $12 \mathrm{~h}$ and ST-segment elevations of $>2 \mathrm{~mm}$ in at least two contiguous leads.

All patients underwent acute coronary angiography and, if eligible, direct or rescue angioplasty. All interventions were performed according to current standard guidelines [19-21].

As a pharmacological regimen, all patients received $500 \mathrm{mg}$ Aspirin orally, $300 \mathrm{mg}$ Clopidogrel and a weight adapted bolus of intravenous heparin (100 IE/ $\mathrm{kg}$ ) upon admission prior to entering the cathlab. A weight-adapted bolus $(0.25 \mathrm{mg} / \mathrm{kg})$ of abciximab (Reopro ${ }^{\circledR}$, Lilly Corp) was also administered in all patients, with the exception of those who received prehospital fibrinolytic therapy. Administration of abciximab was established in our center as good clinical practice after data of positive impact in patients undergoing primary PCI came up $[7,9,11]$. Other medications, including betablockers, nitrates, and morphine were administered at the discretion of the physician on duty.

The antegrade radiocontrast flow of the infarctrelated artery was determined on the final coronary angiogram by the operator with the use of TIMI criteria. The TIMI flow grades have been defined previously [22]. In brief, grade 0 perfusion is no antegrade flow beyond the point of occlusion; grade 1 is minimal incomplete perfusion of contrast medium around the clot; grade 2 (partial perfusion) is complete but delayed perfusion of the distal coronary bed with contrast material; and grade 3 (complete perfusion) is antegrade flow to the entire distal bed at a normal rate.

All patients were invited for a follow-up visit 6 months after index hospitalisation. Clinical status and 12 lead ECGs were performed routinely. An exercise test was also performed at the discretion of the physician.

\section{Statistical analysis}

A multivariate binary logistic regression analysis was performed to determine which clinical and angiographic variables would independently predict poor post-interventional coronary flow (TIMI flow $\leq 2$ ). Variables with a $P$-value $<0.05$ were considered statistically significant as independent predictors.

Values are expressed as mean \pm standard deviation or frequencies. Differences in continuous variables were analyzed using the Student's $t$ test. $P$-values $<0.05$ were considered statistically significant.

\section{Results}

\section{Baseline characteristics}

The baseline characteristics are listed in Table 1. Five hundred patients underwent primary angioplasty for myocardial infarction. In all, 70 patients (14\%), 21 (30\%) female, did not show TIMI 3 flow after intervention. The number of patients with TIMI 0.1 , and two flows were 32 patients (46\%), 12 patients (17\%) and 26 patients $(37 \%)$ respectively. In 430 patients $(86 \%), 111$ female $(25.8 \%)$, the procedure was considered complete after establishing TIMI 3 flow. In 419 out of the 430 patients with post procedural TIMI 3 flow, TIMI 3 flow was established by PCI. In 11 patients $(2.6 \%)$ angioplasty was not performed for various reasons. In three patients, a pericarditis was diagnosed. Seven patients did not show angiographic stenosis $\geq 50 \%$. These 10 patients $(2 \%)$ were excluded from our analysis because no significant stenosis in

Table 1 Baseline characteristics of patients undergoing acute coronary angiography

\begin{tabular}{lccl}
\hline & $\begin{array}{l}\text { TIMI flow }=3 \\
(n=430) \\
n(\%)\end{array}$ & $\begin{array}{l}\text { TIMI flow } \leq 2 \\
(n=70) \\
n(\%)\end{array}$ & \\
& $61(13)$ & $64(14)$ & 0.049 \\
& $111(25.8)$ & $21(30)$ & 0.086 \\
Age (SD); years & $292.6(527.9)$ & $341.9(558.7)$ & 0.231 \\
Female & & & \\
Onset of symptom & & & \\
$\quad$ to hospital (SD), min & $230(53.5)$ & $32(45.7)$ & 0.05 \\
History & $58(13.5)$ & $19(27.1)$ & 0.003 \\
$\quad$ Hypertension & $216(50.2)$ & $38(54.3)$ & 0.084 \\
$\quad$ Diabetes & $123(28.6)$ & $18(25.7 \%)$ & 0.103 \\
$\quad$ Hypercholesterolemia & $13(3.0)$ & $5(7.1)$ & 0.064 \\
Prior PCl or myocardial infarction & $135(31.4)$ & $20(28.5)$ & 0.101 \\
$\quad$ Prior bypass surgery & $27(6.3)$ & $10(14.3)$ & 0.015 \\
$\quad$ Current tobacco smoker & & & \\
$\quad$ Prehospital thrombolytic therapy & & & \\
Clinical presentation & $203(47.2)$ & $40(57.1)$ & 0.032 \\
$\quad$ Killip class > 1 & $47(10.9)$ & $17(24.3)$ & 0.002 \\
$\quad$ Cardiogenic shock & & & \\
\hline
\end{tabular}

$S D$ standard deviation, $P C l$ percutaneous coronary intervention 
the coronary arteries could be found. In one patient coronary morphology was not suitable for PCI and was therefore sent for acute coronary artery bypass grafting (CABG).

Of the 70 patients with post procedural TIMI flow $\leq 2$, PCI was performed in 57 patients. 13 patients did not undergo angioplasty for various reasons. In 10 cases, PCI was not performed for technical reasons and patients were treated conservatively. One patient exhibited a closed Ramus obliquus as the target vessel, which was therefore not suitable for PCI. One patient was sent for acute coronary artery bypass grafting $(C A B G)$ as a result of a left main stem stenosis in a three vessels disease. In another patient, peripheral coronary embolism lead to ischemia and the vessel was not suitable for PCI. The interventional success rate was $82.6 \%$ in this cohort. The overall success rate was $97.6 \%$ (476 patients out of 488).

Compared with the cohort with TIMI 3 flow, those with TIMI flow $\leq 2$ were significantly more likely to be older, diabetic, hypertensive, and had unsuccessful prehospital fibrinolytic therapy with an indication for a "rescue PCI". Similarly, presentation with cardiogenic shock, defined as adverse hemodynamics such as heart rate $>100$ beats/min and blood pressure $<100 \mathrm{mmHg}$, despite adequate fluid administration, was more common in patients with TIMI flow $\leq 2$.

There was also a trend towards a longer period of chest pain in patients with post-interventional TIMI flow $\leq 2$. However, due to a large standard deviation, a statistically significant difference was not observed.

\section{Angiographic results and clinical outcome}

Angiographic characteristics differed between the two patient groups. In this analysis, only those patients with significant coronary artery stenosis $(n=490)$ were included. As mentioned previously, ten patients did not undergo revascularisation (Tables 2 and 3).

Thus, patients with TIMI flow $\leq 2$ were more likely to have initial TIMI flow $\leq 1(P=0.015)$, left anterior descending and saphenous vein grafts as infarct-related artery, a left ventricular ejection fraction $<50 \%$, and were more likely to undergo rescue PCI after prehospital intravenous thrombolytic therapy and treatment with an intra-aortic balloon pump $(P=0.045)$.

There was a significant difference observed in overall mortality during index hospitalization between patients who achieved TIMI flow $\leq 2$ and TIMI flow 3 (32.9 Vs. $6.4 \%, P<0.0001)$ after their primary PCI. Follow-up mortality after 6 months was not statistically different between the two groups.

However, presentation of New York heart association classification (NYHA-Class) at the 6-month
Table 2 Angiographic data of patients showing significant coronary artery stenosis

\begin{tabular}{lccc}
\hline & $\begin{array}{l}\text { TIMI flow }=3 \\
(n=420) \\
n(\%)\end{array}$ & $\begin{array}{l}\text { TIMI flow } \leq 2 \\
(n=70) \\
n(\%)\end{array}$ & $\begin{array}{l}\text { P-value } \\
\text { Infarct-related artery }\end{array}$ \\
$\quad$ Left anterior descending & $190(45.2)$ & $38(54.3)$ & 0.039 \\
Left circumflex & $67(16)$ & $10(14.3)$ & 0.137 \\
Right coronary & $152(36.2)$ & $17(24.3)$ & 0.016 \\
Saphenous vein graft & $6(1.4)$ & $4(5.7)$ & 0.033 \\
Left main & $5(1.2)$ & $1(1.4)$ & 0.399 \\
Three vessels disease & $76(18.1)$ & $19(27.1)$ & 0.027 \\
Initial TIMI flow & & & \\
0 & $265(63.1)$ & $49(70)$ & 0.059 \\
1 & $62(14.8)$ & $13(18.6)$ & 0.097 \\
2 & $52(12.4)$ & $8(11.4)$ & 0.155 \\
3 & $41(9.7)$ & $0(0)$ & 0.0013 \\
Post-procedure TIMI flow & & & \\
0 & $0(0)$ & $32(45.7)$ & \\
1 & $0(0)$ & $12(17.1)$ & \\
2 & $0(0)$ & $26(37.2)$ & \\
3 & $420(100)$ & $0(0)$ & \\
Intra-aortic balloon pump & $25(5.9)$ & $8(11.4)$ & 0.045 \\
Stentthrombosis & $34(7.9)$ & $6(8.6)$ & 0.179 \\
Left ventricular ejection & $51.3(11.8)$ & $44.2(13.1)$ & 0.00001 \\
fraction (SD) & & & \\
\hline
\end{tabular}

SD standard deviation, TIMI thrombolysis in myocardial infarction

Table 3 Follow up data

\begin{tabular}{lccc}
\hline & $\begin{array}{l}\text { TIMI Flow }=3 \\
(n=420) \\
n(\%)\end{array}$ & $\begin{array}{l}\text { TIMI Flow } \leq 2 \\
(n=70) \\
n(\%)\end{array}$ & P-value \\
\hline In hospital mortality & $27(6.4)$ & $23(32.9)$ & $<0.0001$ \\
6 month follow up & 393 & 47 & \\
Lost of follow up & $18(4.5)$ & $3(6.4)$ & \\
Death & $17(4.2)$ & $2(4.3)$ & 0.293 \\
NYHA I & $183(51.1)$ & $16(38.1)$ & 0.037 \\
NYHA II & $122(34.1)$ & $21(50.0)$ & 0.018 \\
NYHA III & $42(11.7)$ & $3(7.1)$ & 0.155 \\
NYHA IV & $11(3.1)$ & $2(4.8)$ & 0.258 \\
Cardiac catheterization & $133(37.2)$ & $23(54.7)$ & 0.012 \\
TVR & $52(39.1)$ & $4(17.4)$ & 0.025 \\
PCI of non target vessel & $22(16.6)$ & $4(17.4)$ & 0.232 \\
ad CABG & $4(3.0)$ & 0 & \\
\hline
\end{tabular}

NYHA New York Heart Association, TVR target vessel revascularization, $P C$ I percutaneous coronary intervention, $C A B G$ coronary artery bypass grafting, TIMI thrombolysis in myocardial infarction

follow-up visit was significantly different. Patients with TIMI flow $\leq 2$ were more likely to present in NYHA class $\geq 1$ and to undergo repeated coronary angiography. However, target vessel revascularisation in these catheterizations was performed more often in the patients with post-interventional TIMI flow 3 $(P=0.025)$. 
Table 4 Logistic regression analysis for independent predictors of postinterventional TIMl flow $\leq 2$

\begin{tabular}{|c|c|c|c|c|}
\hline Variable & $\begin{array}{l}\text { Beta } \\
\text { coefficient }\end{array}$ & $\begin{array}{l}\text { Standard } \\
\text { error }\end{array}$ & $\begin{array}{l}P \text {-value } \begin{array}{l}\text { Odds } \\
\text { ratio }\end{array}\end{array}$ & $\begin{array}{l}95 \% \text { confidence } \\
\text { intervall }\end{array}$ \\
\hline Cardiogenic shock & 0.993 & 0.326 & $0.002 \quad 2.700$ & $1.425-5.116$ \\
\hline Three vessel disease & 0.877 & 0.294 & $0.003 \quad 2.404$ & $1.351-4.277$ \\
\hline $\begin{array}{l}\text { Prehospital thrombolytic } \\
\text { therapy }\end{array}$ & 0.976 & 0.408 & 0.0172 .653 & $1.191-5.906$ \\
\hline Diabetes mellitus & 0.781 & 0.316 & 0.0132 .185 & $1.176-4.060$ \\
\hline Constant & -2.482 & 0.201 & $<0.001 \quad 0.084$ & \\
\hline
\end{tabular}

TIMI thrombolysis in myocardial infarction

\section{Predictors of TIMI flow $\leq 2$}

Resorting to stepwise logistic regression, four independent predictors of TIMI flow $\leq 2$ were identified: prehospital thrombolytic therapy, cardiogenic shock, three vessel disease, and diabetes mellitus. The most powerful predictors were cardiogenic shock and three vessel disease. Prehospital thrombolytic therapy and diabetes mellitus were also associated with a higher probability of a TIMI flow $\leq 2$. The overall predictability of the regression model was $85.8 \%$ (Table 4 ).

\section{Discussion}

Successful reperfusion therapy, achieved through mechanical or pharmacological intervention, is the goal in the treatment of patients with STEMI $[3,10,18]$.

The objective of all interventions is restoration of normal TIMI 3 flow within the epicardial coronary vessels. Time to reperfusion is an important factor in this topic, as described previously [5,23]. This could give an account for worse outcome in patients after unsuccessful prehospital fibrinolytic therapy with an indication for a "rescue PCI". Rescue patients evolve larger infarctions, likely explained by delay to reperfusion [4]. On the other hand we did not administer abciximab in these patients which might additionally have an impact on TIMI flow and clinical outcome. For this topic further investigation is needed in order to establish therapeutical regimen with GPIIb/ IIIa antagonists on top of a failed thombolytic therapy.

The study populations in previously published data discussing the influence of TIMI flow on angiographic and clinical results are different from the study population evaluated here. Previous studies excluded patients after prehospital fibrinolysis, and patients with cardiogenic shock, renal insufficiancy, or those with child-bearing potential (unless the result of a recent pregnancy test was negative) [12], or compared different therapeutical regimens [6].

We present data of a single center "real world cohort" of 500 patients admitted to our hospital with
STEMI. As PCI was attempted in many patients that would have been excluded in former randomized trials, restoration was not feasible in all patients despite high levels of technical experience amongst the operators, as an overall success rate of $97.6 \%$ indicates.

Putative mechanisms for suboptimal post-interventional epicardial coronary flow, known as "no reflow phenomenon", may be a multi-factor condition reflecting damage to microvascular integrity incurred both during ischemia and at the time of reperfusion. Possible related factors are microvascular damage or edema, neutrophil plugging of the microvessels, micorovascular spasm, distal embolization of thrombus, and debris, or poor PCI result with a significant residual stenosis, dissection, or mural thrombosis $[13,14,16,17]$.

The post-interventional TIMI flow is an important prognostic value for in-hospital mortality and clinical outcome 6 months post-hospitalization [8].

This analysis of a "real world patient cohort" demonstrates that the success rate of primary PCI is lower in older patients than in younger patients, and this finding is associated with a higher mortality with primary PCI during STEMI in elderly patients. In addition, patients with STEMI showing the left anterior descending coronary artery or saphenous vein grafts as the culprit vessel are more likely to have poor final coronary blood flow.

Overall, age, clinical presentation, and infarct localization appear to be important factors impacting the outcome in patients with STEMI undergoing primary PCI. Predictors for poor post-interventional flow in the coronary arteries are three vessels disease, cardiogenic shock, diabetes mellitus, and inefficient prehospital thrombolytic therapy.

A finding that has not been previously described is that patients undergoing rescue PCI due to inefficient intravenous fibrinolytic therapy have a post-interventional TIMI flow $\leq 2$ significantly more often. These findings warrant further evaluation. It is most plausible that the mechanisms described above result in impaired flow in the coronary arteries if pharmacological reperfusion is not successful.

Patients with TIMI flow $\leq 2$ exhibited worse NYHA class at the 6 month follow-up visit, requiring coronary angiography more frequently at this timepoint in order to obtain invasive control. However, the rate of target vessel revascularisation following the decision to obtain invasive control at the 6 month follow-up visit was significantly lower in these patients. This may, on the one hand, be the result of the higher incidence of three vessel disease in these patients, without the need for another PCI (total chronic occlusion; no angiographic significant stenosis $(<60 \%))$. On the other hand, as is the case in this patient group, age is associated with higher levels of sclerosis in the small lumen diameter vessels, without the possibility of mechanical 
intervention resulting in stable angina upon long term follow up.

\section{Conclusion}

The inability to achieve successful coronary reperfusion is associated with a higher mortality in patients with acute myocardial infarction undergoing primary angioplasty. Prehospital fibrinolytic therapy, age, and infarct localisation increase the risk of poor final coronary blood flow. Post- interventional TIMI flow $\leq 2$ is associated with a worse NYHA class at a 6 month follow-up visit, requiring a significantly higher number of repeated coronary angiograms to assess invasive coronary status.

\section{References}

1. Antman EM, Anbe DT, Armstrong PW, Bates ER, Green LA, Hand M, Hochman JS, Krumholz HM, Kushner FG, Lamas GA, Mullany CJ, Ornato JP, Pearle DL, Sloan MA, Smith SC Jr, Alpert JS, Anderson JL, Faxon DP, Fuster V, Gibbons RJ, Gregoratos G, Halperin JL, Hiratzka LF, Hunt SA, Jacobs AK, Ornato JP (2004) ACC/AHA guidelines for the management of patients with ST-elevation myocardial infarction; A report of the American College of Cardiology/American Heart Association Task Force on Practice Guidelines (Committee to revise the 1999 guidelines for the management of patients with acute myocardial infarction). J Am Coll Cardiol 44(3):E1-E211

2. Boden WE, Eagle K, Granger CB (2007) Reperfusion strategies in acute STsegment elevation myocardial infarction: a comprehensive review of contemporary management options. J Am Coll Cardiol 50(10):917-929

3. Boersma E, Mercado N, Poldermans D, Gardien M, Vos J, Simoons ML (2003) Acute myocardial infarction. Lancet 8;361(9360):847-858

4. Buller CE, Welsh RC, Westerhout CM, Webb JG, O'Neill B, Gallo R, Armstrong PW (2008) Guideline adjudicated fibrinolytic failure: incidence, findings, and management in a contemporary clinical trial. Am Heart J 155(1):121-127

5. Chung WY, Han MJ, Cho YS, Kim KI, Chang HJ, Youn TJ, Chae IH, Choi DJ, Kim $\mathrm{CH}$, Oh BH, Park YB, Choi YS (2007) Effects of the early administration of heparin in patients with STelevation myocardial infarction treated by primary angioplasty. Circ J 71(6):862-867

6. Cura FA, L'Allier PL, Kapadia SR, Houghtaling PL, Dipaola LM, Ellis SG, Topol EJ, Brener SJ, GUSTO IIb and RAPPORT Investigators (2001) Predictors and prognosis of suboptimal coronary blood flow after primary coronary angioplasty in patients with acute myocardial infarction. Am J Cardiol 88(2):124-128
7. Iijima R, Ndrepepa G, Mehilli J, Neumann FJ, Schulz S, ten Berg J, Bruskina O, Dotzer F, Dirschinger J, Berger PB, Schömig, Kastrati A (2008) Troponin level and efficacy of abciximab in paients with acute coronary syndromes undergoing early intervention after clopidogrel pretreatment. Clin Res Cardiol 97(3):160-168

8. Ito $\mathrm{H}$, Okamura $A$, Iwakura $\mathrm{K}$, Masuyama T, Hori M, Takiuchi S, Negoro S, Nakatsuchi Y, Taniyama Y, Higashino $\mathrm{Y}$, Fujii $\mathrm{K}$, Minamino $\mathrm{T}$ (1996) Myocardial perfusion patterns related to thrombolysis in myocardial infarction perfusion grades after coronary angioplasty in patients with acute anterior wall myocardial infarction. Circulation 93:1993-1999

9. Kandzari DE, Hasselblad V, Tcheng JE, Stone GW, Califf RM, Kastrati A, Neumann FJ, Brener SJ, Montalescot G, Kong DF, Harrington RA (2004) Improved clinical outcomes with abciximab therapy in acute myocardial infarction: a systematic overview of randomized clinical trials. Am Heart J 147(3):457-462

10. Kurowski V, Giannitsis E, Killermann DP, Wiegand UK, Toelg R, Bonnemeier H, Hartmann F, Katus HA, Richardt G (2008) The effects of facilitated primary PCI by guide wire on procedural and clinical outcomes in acute ST-segment elevation myocardial infarction. Clin Res Cardiol 96(8):557-565

11. Maioli M, Bellandi F, Leoncini M, Toso A, Babizzi RP (2007) Randomized early versus late abciximab in acute myokardial infarction treated with primary coronary intervention (RELAx-AMI trial). J Am Coll Cardiol 49(14):1517-1524

12. Mehta RH, Harjai KJ, Cox D, Stone GW, Brodie B, Boura J, O’Neill W, Grines CL, Primary Angioplasty in Myocardial Infarction (PAMI) Investigators (2003) Clinical and angiographic correlates and outcomes of suboptimal coronary flow inpatients with acute myocardial infarction undergoing primary percutaneous coronary intervention. J Am Coll Cardiol 42(10):1739-1746
13. Morishima I, Sone T, Okumura K, Tsuboi H, Kondo J, Mukawa H, Matsui $\mathrm{H}$, Toki $\mathrm{Y}$, Ito $\mathrm{T}$, Hayakawa $\mathrm{T}$ (2000) Angiographic no-reflow phenomenon as a predictor of adverse long-term outcome in patients treated with percutaneous transluminal coronary angioplasty for first acute myocardial infarction. J Am Coll Cardiol 36(4):1202-1209

14. Piana RN, Paik GY, Moscucci M, Cohen DJ, Gibson CM, Kugelmass AD, Carrozza JP Jr, Kuntz RE, Baim DS (1994) Incidence and treatment of 'no-reflow' after percutaneous coronary intervention. Circulation 89(6):2514-2518

15. Pohlen M, Bunzemeier H, Husemann W, Roeder N, Breithart G, Reinecke H (2008) Risk predictors for adverse outcomes after percutaneous coronary interventions and their related costs. Clin Res Cardiol 97(7):441-448

16. Reffelmann T, Kloner R (2002) The "noreflow" phenomenon: basic science and clinical correlates. Heart 87:162-168

17. Rezkalla SH, Kloner RA (2002) No-reflow phenomenon. Circulation 105(5):656-662

18. Ribichini F, Ferrero V, Wijns W (2004) Reperfusion treatment of ST-elevation acute myocardial infarction. Prog Cardiovasc Dis 47(2):131-157

19. Ryan TJ, Baumann WB, Kennedy JW, Kereiakes DJ, King SB 3rd, McCallister BD, Smith SC Jr, Ullyot DJ (1993) Guidelines for percutaneous transluminal coronary angioplasty: a report of the American Heart Association/ American College of Cardiology Task Force on assessment of diagnostic and therapeutic cardiovascular procedures (Committee circulation on percutaneous transluminal coronary angioplasty). Circulation 88(6):2987-3007

20. Silber S, Albertsson P, Aviles FF, Camici PG, Colombo A, Hamm C, Jorgensen E, Marco J, Nordrehaug JE, Ruzyllo W, Urban P, Stone GW, Wijns W (2005) Guidelines for percutaneous coronary interventions: the task force for percutaneous coronary interventions of the European Society of Cardiology. Eur Heart J 26(8):804-847 
21. Smith SC Jr, Feldman TE, Hirshfeld JW Jr, Jacobs AK, Kern MJ, King SB 3rd, Morrison DA, O'Neill WW, Schaff HV, Withlow PL, Williams DA, Antman EM, Adams CD, Anderson JL, Faxon DP, Fuster V, Halperin JL, Hiratzka LF, Hunt SA, Nishimura R, Ornato JP, Page RL, Riegel B (2006) ACC/AHA/SCAI 2005 guideline update for percutaneous coronary intervention-summary arti- cle: a report of the American College of Cardiology/American Heart Association Task Force on practice guidelines (ACC/AHA/SCAI Writing Committee to update the 2001 guidelines for percutaneous coronary intervention). Circulation 113(1):156-175

22. The TIMI Study Group (1985) The thrombolysis in myocardial infarction (TIMI) trial. NEJM 312(Suppl):932-936
23. Yip HK, Chen MC, Chang HW, Hang CL, Hsieh YK, Fang CY, Wu CJ (2002) Angiographic morphologic features of infarct-related arteries and timely reperfusion in acute myocardial infarction: predictors of slow-flow and no-reflow phenomenon. Chest 122(4): 1322-1332 